\title{
The influence of handling on the elasticity of addition silicone putties
}

\section{Influência da manipulação na elasticidade de siliconas de adição em consistência de massa}

\author{
Leonardo Eloy Rodrigues Filho* \\ Antonio Muench** \\ Carlos Francci* \\ Angelika Katia Luebke ${ }^{* * *}$ \\ Andréia Aparecida Traina***
}

\begin{abstract}
The handling of vinyl polysiloxane (addition silicone) impression putties with latex gloves is said to interfere with the setting of these impression materials. The aim of this study is to evaluate the effect of handling techniques on the setting of vinyl polysiloxane impression putties using several types of gloves. The setting of these materials was evaluated by means of an elasticimeter. Four vinyl polysiloxane putty impression materials and five brands of gloves (one made of vinyl, one of synthetic rubber, and three of natural rubber) were studied. Based on the type of glove, they were previously washed or not, and a spatula was used or not for initial mixing (before handmixing). The vinyl, the synthetic and one of the natural rubber gloves did not require the previous washing procedure and/or the use of a spatula for initial mixing. Two other natural rubber gloves - depending on the silicone -, showed satisfactory results only when the initial mixing was performed with a spatula. It was concluded that setting inhibition depends on the kind of vinyl polysiloxane impression material and the kind of gloves used, but when the initial mixing was performed with the spatula this setting inhibition was overcome. The results of this study also showed that it is possible to associate cross-contamination control and satisfactory performance of addition silicone putty materials. When doubts arise from the compatibility between vinyl polysiloxane impression putties and gloves, the initial mixing should be performed with a spatula.
\end{abstract}

DESCRIPTORS: Silicones; Elasticity; Control groups; Dental materials.

RESUMO: A finalidade da presente pesquisa foi avaliar a influência na elasticidade da manipulação de silicones de adição em consistência de massa, por meio de várias técnicas, empregando-se luvas. A polimerização dos materiais foi avaliada por meio de um elasticimetro. Ensaiaram-se quatro silicones, empregando cinco marcas de luvas (uma de vinil, uma de borracha sintética e três de borracha natural). Dependendo do tipo de luva, ela foi lavada ou não e ainda foi utilizada ou não uma espátula para a mistura inicial dos silicones. Os resultados demonstraram que no emprego das luvas de vinil, uma das de borracha sintética e uma das de borracha natural não precisaram ser lavadas, nem a utilização de espátula para a mistura inicial foi necessária. Duas luvas de borracha natural não conduziram a resultados satisfatórios com todos os silicones sem que a mistura inicial fosse feita com a espátula mas, com essa prática, todas as luvas foram compativeis com todos os silicones. Pode-se concluir que, em caso de dúvida sobre a compatibilidade entre tipo de luva e marca de silicone, o emprego de espátula na mistura inicial contorna o problema.

DESCRITORES: Silicones; Elasticidade; Grupos de controle; Materiais dentários.

\section{INTRODUCTION}

The constant effort in the development of new materials has allowed a clinical practice with improved quality. Among the impression materials, the release of addition silicones represented a great advance in dentistry, since they fulfill several important requirements for impression materials such as dimensional stability, ease of handling and compatibility with model materials. Due to these reasons, addition silicones have become one of the most preferable impression materials with the largest number of indications.

At the same time, the possible exposure of staff members to the transmission of infectious agents has given rise to concerns with cross-infection control in order to prevent cross-contamination. Among the adopted precautions, the routine use of

*Assistant Professors; **Professor; ***Graduate Students - Dental Materials Department, School of Dentistry, University of São Paulo. 
Rodrigues Filho LE, Muench A, Francci C, Luebke AK, Traina AA. The influence of handling on the elasticity of addition silicone putties. Pesqui Odontol Bras 2003;17(3):254-60.

disposable gloves, mainly latex ones, is an essential measure to break the chain of infection ${ }^{2,13,16}$.

However, some papers have shown that the handling of some addition silicones with latex gloves may alter the setting of these materials ${ }^{3,4,10,13,14}$. Cook and Thomaz ${ }^{7}$ showed that if gloves are first washed, the level of setting inhibition is reduced. These results, however, were not confirmed by Kahn and Donovan's ${ }^{8}$ study. Other authors ${ }^{7,9,14,15}$ verified that vinyl or synthetic latex gloves may not inhibit the setting of vinyl polysiloxane putty impression materials, which also lead to the recommendation of a routine use of synthetic latex gloves $^{6}$.

Causton et $a .^{5}$ verified that dithiocarbamatebased chemicals used in the manufacturing procedures of many latex glove types were a probable factor responsible for the inhibition of the setting of vinyl polysiloxane putty impression materials. They recommended the use of dithiocarbamatefree gloves.

Several doubts still remain regarding the compatibility between disposable gloves and polysiloxane impression materials. Therefore, the evaluation of the effects of different handling conditions on the elasticity of different addition silicone brands, including different types of gloves, previously washed or not and with the use of a spatula for initial mixing or not, may contribute to this matter.

\section{MATERIAL AND METHODS}

Four vinyl polysiloxane putty impression materials were studied: (1) Aquasil (Dentsply Detrey, Konstanz, Germany); (2) Express STD (3M Dental Products Division, St. Paul, MN, USA); (3) President (Coltene, Altstätten, Switzerland) and (4) Provil (Bayer, Leverkusen, Germany).

Five brands of gloves were used to mix the impression silicones: one of vinyl: (1) Sensitive (Precious Mountain Enterprise Corp., Taipei, Taiwan); one of synthetic rubber: (2) Safeskin (Safeskin Corp., San Diego, CA, USA); and three of natural rubber: (3) Septol (Produits Dentaires Pierre Roland, Bordeaux, France), (4) Safederm (Powercraft, Kuala Lumpur, Malaysia) and (5) Satari (Siam Supermed Corp., Bangkok, Thailand).

Some gloves (Sensitive - vynil; Safeskin - natural rubber) were used only under a non-washed condition, since they have already presented good compatibility with the silicone putties ${ }^{7,9,14,15}$, a behavior also noted in our preliminary tests. The ot- her gloves (natural rubber) were used under washed and non-washed conditions, since under this condition compatibility may be better ${ }^{7}$ or not ${ }^{8}$. Under the washed condition, they were washed with water and soap, rinsed with water and dried with a towel.

In addition, with some natural rubber gloves (Safederm and Satari), the initial mixing had to be performed with a spatula 36 for about $10 \mathrm{~s}$, in order to obtain the setting of the silicones. But this procedure, as noted in our preliminary tests, was not necessary with the natural rubber glove Septol. For each specimen, a volume of $5 \mathrm{~cm}^{3}$ of the silicones putties was used. Each silicone putty was tested under twelve experimental conditions, which involved washing or not the gloves, and using or not a spatula for initial mixing, as it can be seen on Tables 1 and 2. Provil was an exception since it could not be tested on conditions 5, 6, 9 and 10 (Table 1).

Evaluation of the compatibility among the several brands of addition silicones and glove brands has been studied under several procedures. For instance, Burke, Wilson ${ }^{4}$ and Reitz, Clark ${ }^{14}$ used just an indentation with an instrument to evaluate the setting of the silicones. Rosen et al. ${ }^{15}$ employed an oscillating rheometer similar to that introduced by Wilson ${ }^{17}$. In the present study, the Muench's elasticimeter ${ }^{11}$ was employed, which was also used by Muench and Jansen ${ }^{12}$. This device allows the measurement of the elasticity of impression materials in any polymerization stage, immediately after mixing and up to stages after setting. The tests were performed at $32^{\circ} \mathrm{C}$, based on the ADA compression set test ${ }^{1}$.

The apparatus (Figure 1) consists of a brass plate (A), on which a vertical rod is fixed (B). A cylinder (C) with two steel arms holds the container (D), which lodges the testing material. The container consists of two plastic tubes in which one is fitted inside the other. The inner tube has several perforations to hold the impression material when deformed by the rotation of the mobile $\operatorname{rod}(\mathrm{F})$, by means of the cylindric knob $(\mathrm{H})$. The end of the rod (F) immersed in the container (D) presents axial carves for retention purposes. The rotation of the knob $(\mathrm{H})$ is registered by the indicator $(\mathrm{G})$ on the protractor, which records the described angle. This angle corresponds to the deformation degree of the material inside the container (D). Some graphs permit to obtain the material deformation as a function of this angle. The difference between 
Rodrigues Filho LE, Muench A, Francci C, Luebke AK, Traina AA. The influence of handling on the elasticity of addition silicone putties. Pesqui Odontol Bras 2003;17(3):254-60.

TABLE 1 - Means* and SD (\%) of elastic recovery at the manufacturers' indicated setting time.

\begin{tabular}{c|c|c|c|c|c|c|c}
\hline \hline \multirow{2}{*}{ Condition } & \multicolumn{3}{|c|}{ Gloves } & \multicolumn{4}{c}{ Addition silicone } \\
\cline { 2 - 8 } & Brand & Washed & $\begin{array}{c}\text { Mixed with } \\
\text { spatula }\end{array}$ & Aquasil & Express & President & Provil \\
\hline 1 & Sensitive & $\mathrm{N}$ & $\mathrm{N}$ & $97.3 \pm 2.7 \mathrm{a}$ & $96.1 \pm 2.5 \mathrm{a}$ & $63.4 \pm 9.8 \mathrm{cde}$ & $96.6 \pm 2.2 \mathrm{a}$ \\
\hline 2 & Safeskin & $\mathrm{N}$ & $\mathrm{N}$ & $98.1 \pm 0.0 \mathrm{a}$ & $94.1 \pm 3.2 \mathrm{a}$ & $56.9 \pm 7.5 \mathrm{def}$ & $98.2 \pm 0.5 \mathrm{a}$ \\
\hline 3 & Septol & $\mathrm{N}$ & $\mathrm{N}$ & $89.1 \pm 5.9 \mathrm{abc}$ & $94.4 \pm 0.4 \mathrm{a}$ & $82.0 \pm 4.2 \mathrm{abc}$ & $98.6 \pm 0.8 \mathrm{a}$ \\
\hline 4 & Septol & $\mathrm{Y}$ & $\mathrm{N}$ & $89.6 \pm 1.7 \mathrm{abc}$ & $97.3 \pm 1.1 \mathrm{a}$ & $88.8 \pm 1.8 \mathrm{a}$ & $98.7 \pm 0.7 \mathrm{a}$ \\
\hline 5 & Safederm & $\mathrm{N}$ & $\mathrm{N}$ & $75.1 \pm 2.1 \mathrm{~d}$ & $30.1 \pm 5.6 \mathrm{~b}$ & $85.2 \pm 9.0 \mathrm{ab}$ & - \\
\hline 6 & Safederm & $\mathrm{Y}$ & $\mathrm{N}$ & $90.3 \pm 1.1 \mathrm{abc}$ & $93.2 \pm 1.8 \mathrm{a}$ & $84.5 \pm 10.1 \mathrm{abc}$ & - \\
\hline 7 & Safederm & $\mathrm{N}$ & $\mathrm{Y}$ & $94.4 \pm 1.3 \mathrm{ab}$ & $96.0 \pm 0.4 \mathrm{a}$ & $72.0 \pm 2.9 \mathrm{abcd}$ & $98.1 \pm 0.5 \mathrm{a}$ \\
\hline 8 & Safederm & $\mathrm{Y}$ & $\mathrm{Y}$ & $75.4 \pm 6.8 \mathrm{~d}$ & $98.2 \pm 0.2 \mathrm{a}$ & $70.6 \pm 9.0 \mathrm{abcd}$ & $96.9 \pm 2.4 \mathrm{a}$ \\
\hline 9 & Satari & $\mathrm{N}$ & $\mathrm{N}$ & $83.2 \pm 6.1 \mathrm{bcd}$ & $93.5 \pm 1.9 \mathrm{a}$ & $36.8 \pm 9.4 \mathrm{fg}$ & - \\
\hline 10 & Satari & $\mathrm{Y}$ & $\mathrm{N}$ & $74.0 \pm 5.2 \mathrm{~d}$ & $96.8 \pm 0.9 \mathrm{a}$ & $66.0 \pm 5.3 \mathrm{bcde}$ & - \\
\hline 11 & Satari & $\mathrm{N}$ & $\mathrm{Y}$ & $95.7 \pm 0.8 \mathrm{ab}$ & $97.1 \pm 1.4 \mathrm{a}$ & $23.9 \pm 5.4 \mathrm{~g}$ & $99.5 \pm 0.2 \mathrm{a}$ \\
\hline 12 & Satari & $\mathrm{Y}$ & $\mathrm{Y}$ & $81.4 \pm 7.5 \mathrm{~cd}$ & $97.2 \pm 0.9 \mathrm{a}$ & $45.6 \pm 5.1 \mathrm{ef}$ & $99.5 \pm 0.5 \mathrm{a}$ \\
\hline \hline
\end{tabular}

*Means with same letters for each impression material are not significantly different according to Tukey's multiple-range test (p > 0.05); Y (yes), N (no).

the induced deformation and the residual deformation after release of the mobile rod $(\mathrm{F})$ allows the calculation of the elastic recovery, with $0.1 \%$ precision. If the indicator $(\mathrm{G})$ stays immobile, the elastic recovery is zero. If the indicator returns to the initial position, the elastic recovery is $100 \%$. If the indicator is maintained at an intermediate position, the elastic recovery is calculated based on the initial deformation.

In this study, the mixture of the two pastes of each impression material was performed in accordance with the 12 experimental conditions presented on Tables 1 and 2 . The mixture was placed into the container and the first deformation was induced at the curing time indicated by the manufacturers (3.5 minutes for Aquasil and President, and 5.0 minutes for Express and Provil). The degree of induced deformation was $12 \%$ (held for 2 seconds) and the measurement of the indicator $(\mathrm{G})$ was performed after its stabilization (approximately 20 seconds). Several other deformations were performed sequentially every minute from the first deformation until the acquirement of $100 \%$ elastic recovery, when it was possible to obtain (until 9 minutes). For each experimental condition, 3 specimens were prepared $(\mathrm{n}=3)$.

The elastic recovery data from the first deformation (Table 1) and the time required to reach $100 \%$ of elastic recovery, when obtainable (Table 2), were submitted to statistical analysis. ANOVA was applied to each silicone separately, with the 12 levels of experimental conditions. However, in some instances, it was not possible to obtain 12 experimental conditions either because it was not possible to obtain specimens (Provil under conditions 5, 6, 9 and 10) and/or because a $100 \%$ elastic recovery was not reached (Express under conditions 5 and 6). Tukey's multiple-range test was performed in order to contrast the means $(\alpha=0.05)$.

\section{RESULTS}

Table 1 shows the elastic recovery means and their respective standard deviations (SD) in percentage. Table 2 presents the mean and SD of the time required to reach a $100 \%$ elastic recovery. Similar letters represent similar means ( $p>0.05$ ). Graph 1 represents mean values represented on Tables 1 and 2 .

The Aquasil silicone presents a 3.5-minute setting time (according to the manufacturer). At this time, as shown on Table 1, this material presented different values of elastic recovery depending on the experimental condition. Lower values were measured under conditions 5, 8 and 10. In condition 5 , the Safederm glove (natural rubber), non-washed and not spatulated was used. The same glove was used in condition 8 , but it was washed and a 
Rodrigues Filho LE, Muench A, Francci C, Luebke AK, Traina AA. The influence of handling on the elasticity of addition silicone putties. Pesqui Odontol Bras 2003;17(3):254-60.

TABLE 2 - Means* and SD (min) of time required to reach 100\% elastic recovery.

\begin{tabular}{c|c|c|c|c|c|c|c}
\hline \hline \multirow{2}{*}{ Condition } & \multicolumn{4}{|c|}{ Gloves } & \multicolumn{4}{c}{ Addition silicone } \\
\cline { 2 - 8 } & Brand & Washed & $\begin{array}{c}\text { Mixed with } \\
\text { spatula }\end{array}$ & Aquasil & Express & President & Provil \\
\hline 1 & Sensitive & $\mathrm{N}$ & $\mathrm{N}$ & $4.7 \pm 1.0 \mathrm{ab}$ & $6.2 \pm 0.3 \mathrm{~cd}$ & $7.8 \pm 0.3 \mathrm{a}$ & $7.3 \pm 0.8 \mathrm{a}$ \\
\hline 2 & Safeskin & $\mathrm{N}$ & $\mathrm{N}$ & $4.3 \pm 0.3 \mathrm{~b}$ & $6.8 \pm 0.3 \mathrm{bc}$ & $7.0 \pm 0.5 \mathrm{abc}$ & $6.0 \pm 0.0 \mathrm{ab}$ \\
\hline 3 & Septol & $\mathrm{N}$ & $\mathrm{N}$ & $4.8 \pm 0.6 \mathrm{ab}$ & $7.3 \pm 0.3 \mathrm{ab}$ & $6.5 \pm 0.9 \mathrm{bcd}$ & $5.8 \pm 0.3 \mathrm{~b}$ \\
\hline 4 & Septol & $\mathrm{Y}$ & $\mathrm{N}$ & $5.3 \pm 0.3 \mathrm{ab}$ & $6.3 \pm 0.3 \mathrm{~cd}$ & $5.8 \pm 0.6 \mathrm{~cd}$ & $6.7 \pm 0.8 \mathrm{ab}$ \\
\hline 5 & Safederm & $\mathrm{N}$ & $\mathrm{N}$ & $6.0 \pm 0.5 \mathrm{a}$ & - & $6.0 \pm 0.0 \mathrm{~cd}$ & - \\
\hline 6 & Safederm & $\mathrm{Y}$ & $\mathrm{N}$ & $5.2 \pm 0.3 \mathrm{ab}$ & - & $5.7 \pm 0.3 \mathrm{~d}$ & - \\
\hline 7 & Safederm & $\mathrm{N}$ & $\mathrm{Y}$ & $4.7 \pm 0.3 \mathrm{ab}$ & $6.5 \pm 0.5 \mathrm{bcd}$ & $7.0 \pm 0.0 \mathrm{abc}$ & $5.7 \pm 0.3 \mathrm{~b}$ \\
\hline 8 & Safederm & $\mathrm{Y}$ & $\mathrm{Y}$ & $5.7 \pm 0.3 \mathrm{ab}$ & $6.5 \pm 0.0 \mathrm{bcd}$ & $6.5 \pm 0.5 \mathrm{bcd}$ & $6.3 \pm 0.8 \mathrm{ab}$ \\
\hline 9 & Satari & $\mathrm{N}$ & $\mathrm{N}$ & $6.0 \pm 0.5 \mathrm{a}$ & $8.0 \pm 0.5 \mathrm{a}$ & $7.3 \pm 0.3 \mathrm{ab}$ & - \\
\hline 10 & Satari & $\mathrm{Y}$ & $\mathrm{N}$ & $6.0 \pm 0.5 \mathrm{a}$ & $6.2 \pm 0.3 \mathrm{~cd}$ & $7.3 \pm 0.3 \mathrm{ab}$ & - \\
\hline 11 & Satari & $\mathrm{N}$ & $\mathrm{Y}$ & $5.0 \pm 0.0 \mathrm{ab}$ & $5.8 \pm 0.3 \mathrm{~d}$ & $7.7 \pm 0.3 \mathrm{a}$ & $5.5 \pm 0.0 \mathrm{~b}$ \\
\hline 12 & Satari & $\mathrm{Y}$ & $\mathrm{Y}$ & $6.2 \pm 0.8 \mathrm{a}$ & $5.8 \pm 0.3 \mathrm{~d}$ & $7.5 \pm 0.0 \mathrm{ab}$ & $5.5 \pm 0.0 \mathrm{~b}$ \\
\hline \hline
\end{tabular}

*Means with same letters for each impression material are not significantly different according to Tukey's multiple-range test (p > 0.05); Y (yes), N (no).

spatula was used for initial mixing. In condition 10, the Satari glove (natural rubber) was used, washed and hand mixed (without a spatula). On the other hand, Table 2 and Graph 1 show that in all conditions, Aquasil silicone reached a 100\% elastic recovery in a short period (no more than 6.2 minutes).

FIGURE 1 - Muench's elasticimeter. A (brass stage); B (fixed vertical rod); C (cylinder with steel arms); D (container); E (horizontal bars); F (mobile rod); G (indicator on the protractor); $\mathrm{H}$ (cylindric knob); I (handle).

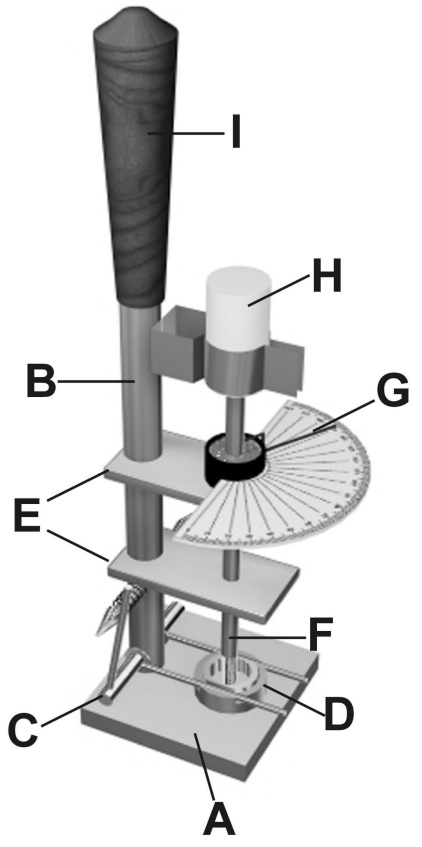

The Express silicone, which presents a 5-minute setting time according to the manufacturer, showed low elastic recovery when it was mixed with the Safederm glove under the non-washed and non-spatulated condition (condition 5). Table 2 shows that the association Express/Safederm, when handled without the use of a spatula, initially prevented the achievement of a $100 \%$ elastic recovery (conditions 5 and 6 - Table 2 and Graph 1).

The President silicone showed generally low elastic recovery when the Satari glove was used (Table 1 and Graph 1). Nevertheless, this silicone, under all the conditions, allowed the achievement of a $100 \%$ elastic recovery (Table 2 and Graph 1).

The Provil silicone remained viscous and sticky when the mixing was performed with the Safederm and Satari gloves without the use of spatula (conditions 5, 6, 9 and 10), which prevented the obtainment of specimens, as shown on Tables 1 and 2 and Graph 1. Regarding the other experimental conditions, the elastic recoveries were acceptable with no detectable significant differences between the tested conditions, reaching a 100\% elastic recovery (Table 2 and Graph 1).

\section{DISCUSSION}

An analysis of the results of this study reveals that they are in accordance with other published 
Rodrigues Filho LE, Muench A, Francci C, Luebke AK, Traina AA. The influence of handling on the elasticity of addition silicone putties. Pesqui Odontol Bras 2003;17(3):254-60.
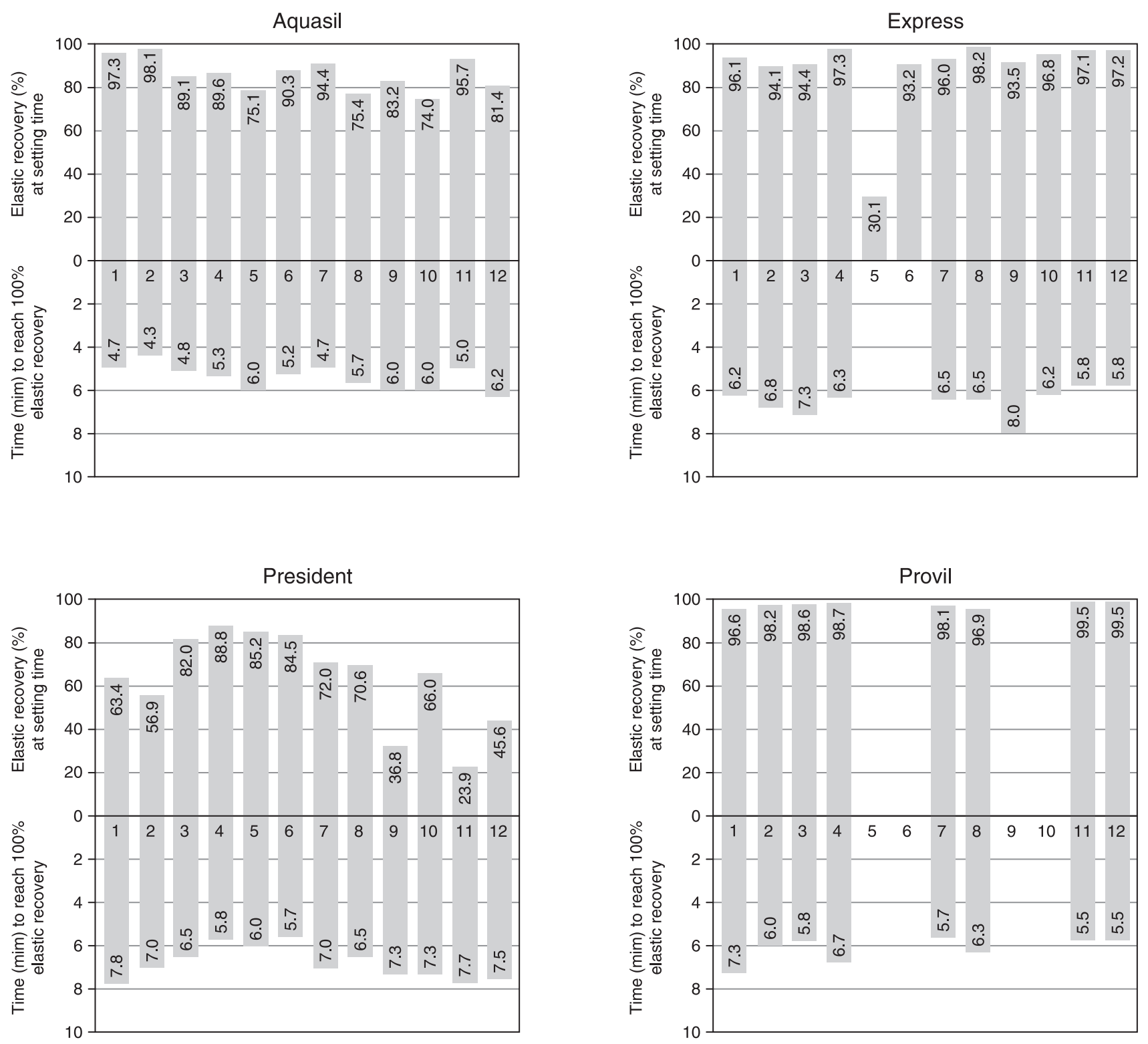

GRAPH 1 - Columns over zero line represent means (\%) of elastic recovery at manufacturer's indicated setting time. Columns below zero line represent means (min) of required time to reach 100\% elastic recovery (conditions 1 to 12 are the correspondent in Tables 1 and 2).

studies presented in the literature, even though with divergent points of view. Kahn, Donovan ${ }^{8}$ concluded that the washing procedure does not improve the results (see conditon 6 with the Safederm glove and the Express and Provil silicones; and condition 10 with the Satari glove and the Provil silicone). Otherwise, in accordance with Bau$\mathrm{mann}^{3}$, not all latex gloves inhibit the setting of addition silicones, which can also be observed on Tables 1 and 2 and Graph 1.
The results of this study are also in accordance with the findings of Neissen et al. ${ }^{13}$. They reported that some types of gloves may prevent some impression materials from setting. Otherwise, our results are not in accordance with Cook, Thomaz ${ }^{7}$, who recommended washing the gloves, since our results were erratic some times as regards this procedure. The results are still in accordance with some authors that claim that not all brands of gloves are incompatible with all silicones ${ }^{13}$. 
Rodrigues Filho LE, Muench A, Francci C, Luebke AK, Traina AA. The influence of handling on the elasticity of addition silicone putties. Pesqui Odontol Bras 2003;17(3):254-60.

It is noteworthy that the non-natural rubber gloves tested such as Sensitive (vinyl) and Safeskin (synthetic rubber), did not affect the setting of any tested addition silicones. This finding is in accordance with the suggestion of Connor ${ }^{6}$ who advised to wear synthetic gloves in place of, or over latex gloves in order to avoid cross infection when addition silicones are to be used. On the other hand, the Septol natural rubber glove showed good compatibility with all tested addition silicones even when it was not washed and the silicones were not initially mixed with a spatula.

The setting inhibition observed is attributed to zinc diethyl dithiocarbamate (a widely used latex accelerator), which is able to retard the setting of addition silicones by inactivation of the platinum catalyst of addition silicones (Baumann ${ }^{3}$ ). Based on that and on the potential for irritancy of this chemical and its derivatives on skin, Causton et al. ${ }^{5}$ recommended to wear dithiocarbamate-free gloves. It is possible that the Septol natural rubber glove does not contain dithiocarbamate.

An important observation must be pointed out from the results of this study. The use of the spatula to initially mix the addition silicone pastes presented a beneficial effect on the elasticity of any tested addition silicones under all experimental conditions. Satisfactory results were obtained in conditions $7,8,11$ and 12 , whether the gloves were washed or not. In principle, this fact may suggest that the adverse effect of contamination of the

\section{REFERENCES}

1. American Dental Association. Council on Dental Materials and Devices. Revised American Dental Association Specification no. 19 for Non-Aqueous Elastomeric Dental Impression Materials. J Am Dent Assoc 1997;94:733-41.

2. American Dental Association. Council on Scientific Affairs and on Dental Practice. Infection control recommendation for the dental office and the dental laboratory. J Am Dent Assoc 1996;127:672-80.

3. Baumann MA. The influence of dental gloves on the setting of impression materials. Br Dent J 1995;179:130-5.

4. Burke FJT, Wilson NHF. Non-sterile gloves: evaluation of seven brands. Dent Update 1987;14:336-9.

5. Causton BE, Burke FJT, Wilson NHF. Implications of the presence of dithiocarbamate in latex gloves. Dent Mater 1993;9:209-13.

6. Connor C. Cross-contamination control in prosthodontic practice. Int J Prosthodont 1991;4:337-44.

7. Cook WD, Thomasz F. Rubber gloves and addition silicone materials. Aust Dent J 1986;31:140. addition silicones occurs at the beginning of the mixture, since after the initial mixture with the spatula, gloved hands were used to complete the homogenization of the silicone pastes. The chlorine platinum catalyst may be, in fact, an initiator or may form an immune complex with the vinyl polysiloxanes, because once the reaction kinetics is reached, the setting could be completed.

Table 1 shows that the setting time of 3.5 minutes informed by the manufacturers of Aquasil and especially President addition silicones might actually be longer, since it was noticed that, in a general view, lower elastic recovery values were obtained with these impression materials at the considered time.

\section{CONCLUSIONS}

1. The results of this study indicated that Aquasil and President addition silicones showed satisfactory results under all experimental conditions, as they reached $100 \%$ elastic recovery.

2. The Express material did not present good compatibility with the Safederm glove, reaching however good elastic recovery when the spatula was used to initially homogenize the mixture.

3. The Provil addition silicone must not be used with Safederm and Satari gloves without the use of a spatula for initial mixture.

4. In case of doubt regarding the compatibility of addition silicones and gloves, the use of a spatula for the initial mixture is advocated.

8. Kahn RL, Donovan TE. A pilot study of polymerization inhibition of poly (vinyl siloxane) materials by latex gloves. Int $\mathrm{J}$ Prosthodont 1989;2:128-30.

9. Kahn RL, Donovan TE, Chee WWL. Interaction of gloves and rubber dam with a poly (vinyl siloxane) impression material: a screening test. Int J Prosthodont 1989;2:342-6.

10. Matis BA, Valadez E. The effect of the use of dental gloves on mixing vinyl polysiloxane putties. J Prosthodont 1997; 6:189-92.

11. Muench A. Determinação da elasticidade em materiais de moldagem durante a presa. Rev Paul Odontol 1992; 14:2-8.

12. Muench A, Jansen WC. Recuperação elástica em função da idade e da ordem de deformação. Rev Odontol Univ São Paulo 1997;11:49-53.

13. Neissen LC, Strassler H, Levinson PD, Wood G, Greenbaum J. Effect of latex gloves on setting time of polyvinylsiloxane putty impression material. J Prosthet Dent 1986; 55:128-9. 
Rodrigues Filho LE, Muench A, Francci C, Luebke AK, Traina AA. The influence of handling on the elasticity of addition silicone putties. Pesqui Odontol Bras 2003;17(3):254-60.

14. Reitz CD, Clark NP. The setting of vinyl polysiloxane and condensation silicone putties when mixed with gloved hands. J Am Dent Assoc 1989;116:371-5.

15. Rosen M, Touyz LZG, Becker PJ. The effect of latex gloves on setting time of polysiloxane putty impression materials. Br Dent J 1989;166:374-5.
16. Takla CS, Cunningham SJ, Horrocks EN, Wilson M. The effectiveness of an elastomeric module dispenser in cross-infection control. J Clin Orthod 1998;32:721-6.

17. Wilson HJ. Elastomeric impression materials. Part 1. The setting material. Br Dent J 1966;121:277-83.

Recebido para publicação em 07/08/02

Enviado para reformulação em 25/02/03 Aceito para publicação em 30/04/03 